\title{
THE EFFECT OF NITROGEN FERTILIZATION ON HEIGHT GROWTH OF DOUGLAS FIR ON A POOR SITE ${ }^{1}$
}

\author{
BY H. KNIGHT ${ }^{2}$
}

\begin{abstract}
Results of ten different nitrogen fertilizer treatments on seven-year-old, planted, open-grown Douglas fir on a low-quality site are presented. Annual height growth and foliar observations were used to indicate response. Results show an increase in height growth from fertilizer applications, except one, when compared to the control. The response to the four-ounce ammonium sulfate treatment suggests this amount to be optimum in this trial. Generally the greatest response was in the larger trees. Four of the fertilizer treatments caused needle defoliation. Two treatments killed trees.
\end{abstract}

\section{INTRODUCTION}

In the Douglas fir region various results have been reported on the effects of fertilizers on the growth of Douglas fir in the field. Walters, Soos and Haddock (1961) found a significant increase in height growth from applications of the commercial fertilizer (6-8-6) to three-year-old planted trees. However there was a variable response to the urea-formaldehyde plus phosphorous fertilizer pellet. Austin and Strand (1960) also found variable responses to these fertilizer pellets. The best treatment was Uramite in combination with superphosphate. It significantly increased height growth and basal stem diameter of two-year-old trees when bracken was removed from the site. Gessel and Walker (1956) reported a marked response to nitrogen fertilizers when applied to 15 to 20-year-old stands growing on poor sites (Site index 80-110 feet at 100 years). Shareef (1955) and Miller (1961) gave further evidence of a significant increase of height and diameter growth of a 40-year-old stand of Douglas fir (Site index 80) to nitrogen fertilization. Bailey (1959) suggested the optimum rate of nitrogen application for this low site stand as 100-200 pounds per acre of nitrogen.

This paper provides further information on the effects of various nitrogen fertilizers and rates of application on the height growth of juvenile Douglas fir on a low-quality site.

\section{Method and Procedure}

The experimental area (Fig. 1) is located on Vancouver Island in the Robertson River Valley about six miles south of Cowichan Lake. The average annual temperature is $49^{\circ} \mathrm{F}$ and the average annual rainfall is $72^{\prime \prime}$, with $6.5^{\prime \prime}$ falling from May to September. The frost free period is 200-300 days.

\footnotetext{
${ }^{1}$ This work was done while the author was a member of the Research Division, British Columbia Forest Service, Victoria, B. C.

${ }^{2}$ Graduate student, College of Forestry, University of Washington, Seattle, Washington, U.S.A.
} 
The soil texture is very coarse and stony (Fig. 2). The site index is about 110 and the area has been severely slash-burned. The profile contains $1.0 \%$ nitrogen in the $A_{0}$ horizon ( $0-1$ inch), $0.14 \%$ in the $A_{2}$ (1-2 inches), $0.02 \%$ in the $B_{1}$ ( $8-10$ inches), and $0.004 \%$ in the $B_{2}$ (24 inches).

Two hundred and seventy-five planted, open-grown, seven-year-old Douglas fir were randomly selected for the trial. There were twenty-five trees in each of the ten treatments and the control. The fertilizers were broadcast from the tips of the outermost branches to the stem and were lightly cultivated in. The applications were made in late March of 1958. A description of the treatments is given in Table 1. Mean annual height growth and foliar observations, which included foliar color change, defoliation, tree vigor and growth initiation, indicated the effect of the fertilizer application.

\section{Mean Annual Height}

Results AND Discussion

Table 2 shows the mean annual height growth of trees from each fertilizer treatment and the control for 1958-60. The data in Table 2 are also presented in Fig. 3 which shows a continuing increase in growth-rate of all treatments except calcium cyanamide when compared to the control. When the percent height growth differences in 1960 from all fertilizer treatments are compared to the control, the largest response has been from the Milorganite $(32.2 \%)$ and the 4-ounce ammonium sulphate $(32.2 \%)$ treatments. The next highest response was to the ammonium phosphate $(28.5 \%)$. These three differences are significant at the $1 \%$ level. Following these, the order of response was: 8-ounce ammonium sulphate $(22.8 \%), 2$-ounce ammonium sulphate $(22.7 \%)$, calcium nitrate $(21.3 \%)$, uramite $(18.8 \%)$, 16-ounce ammonium sulphate $(8.2 \%)$, and 1-ounce ammonium sulphate $(6.4 \%)$. The former three differences are significant at the $5 \%$ level.

It is interesting to note that both the slowly soluble nitrogen fertilizers and the 8-ounce ammonium sulfate were the only treatments to increase the percentage height growth during 1960 as compared with the two previous years. The bar graph (Fig. 3) indicates that all fertilizers except calcium cyanamide persistently increased height growth for three years after fertilization. Persistent effects five years after fertilization were reported by Bailey (1959). This effect is supported by Heilman (1961) who found little loss of nitrogen from the soil 3-8 years after nitrogen fertilization of five 30 to 50 -year-old stands of Douglas fir on coarse glacial soils.

Fig. 4 shows a comparison of the percent height growth as influenced by the rate of ammonium sulfate application. It is seen that the 4-ounce ammonium sulfate treatment produced the maximum growth. The general pattern of growth was the same for each year. The curves rise from the control which was the lowest, to the 1-ounce, 2-ounce, maximate at 4 ounces, and then decrease for the 8-ounce and 16-ounce treatments. The 1-ounce and 16ounce, and the 2-ounce and 8-ounce treatments were almost the same.

Generally there was a greater growth response by the larger trees. This is indicated in Fig. 5 which illustrates the annual height growth of a random selection of 48 trees from all fertilizer plots. This result agrees with Gessel and Walker (1956). In addition this greater response tends to persist. 


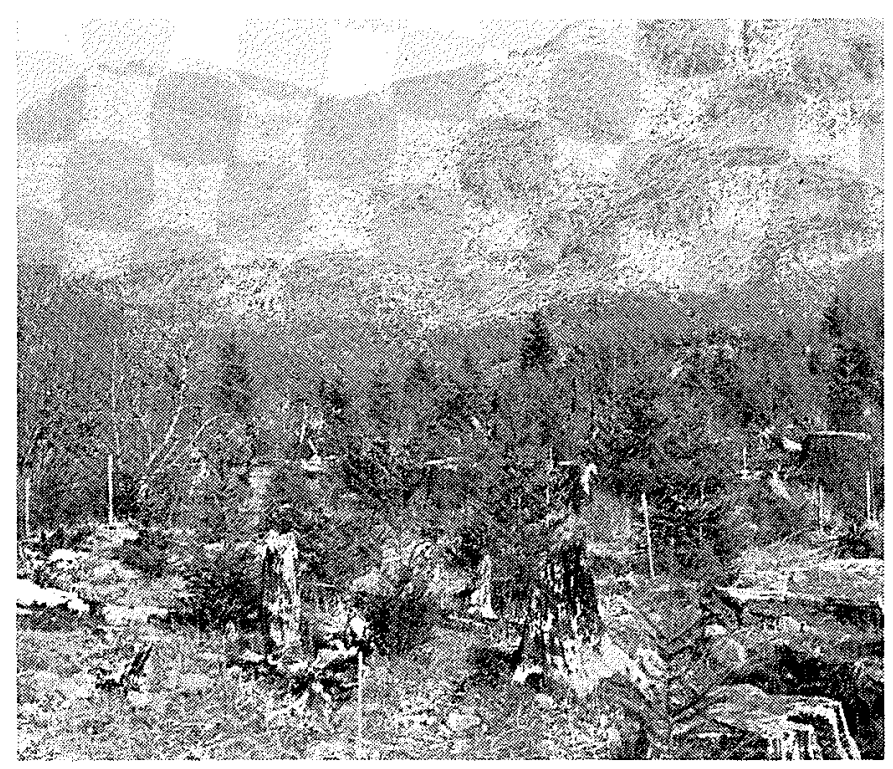

FIGURE 1. View of the experimental area, showing the planted, open-grown juvenile stand of ninc-year-old (in 1960) Douglas fir.

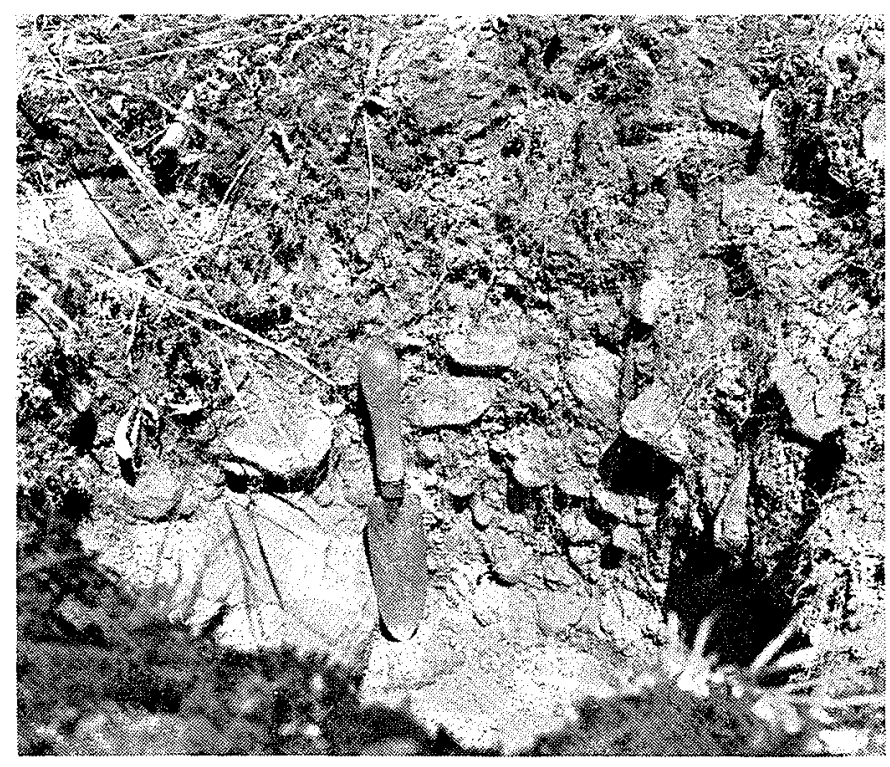

FIGURE 2. Vicw of the soil profile, showing the coarse stony nature of the soil. 


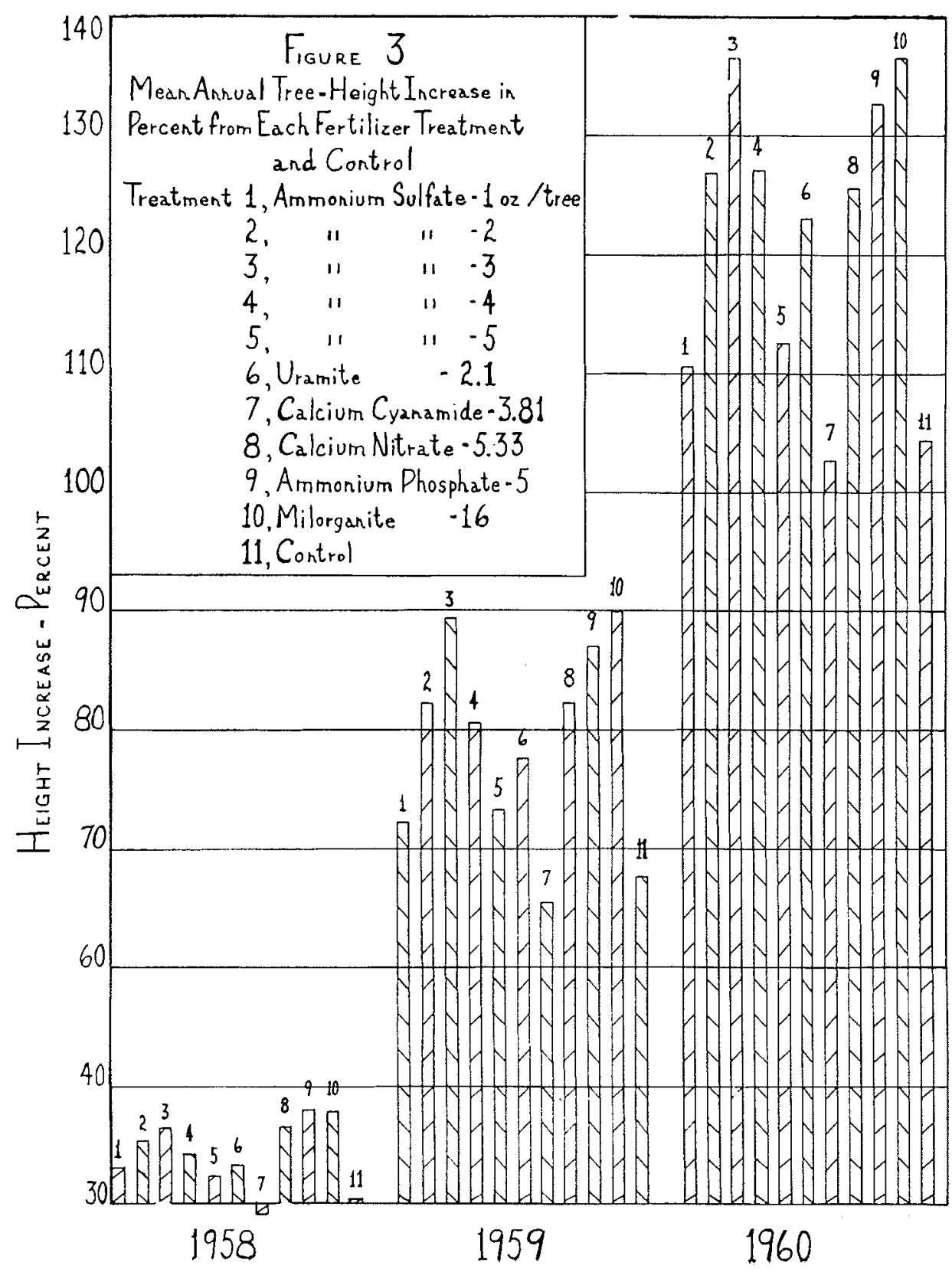




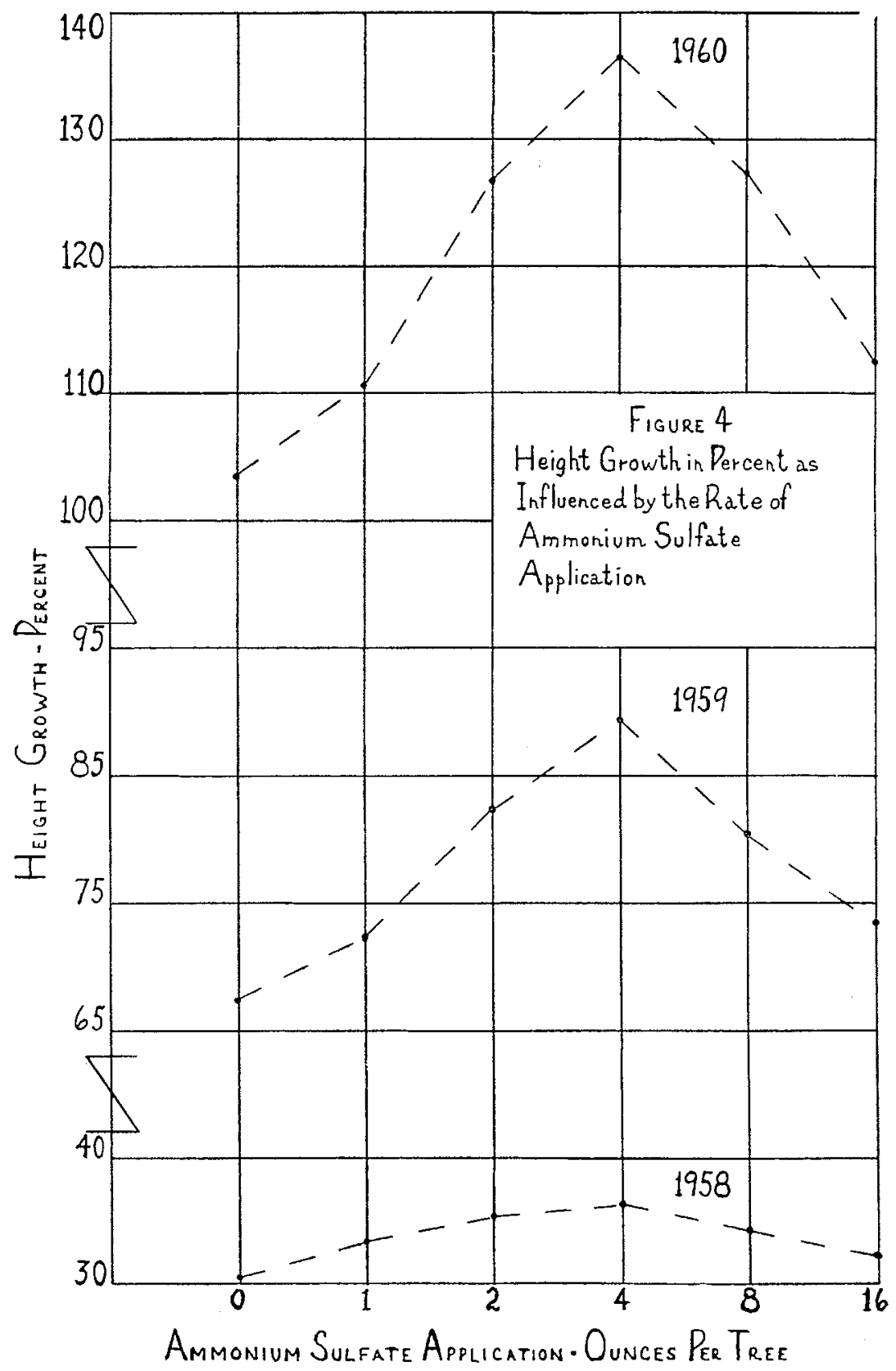




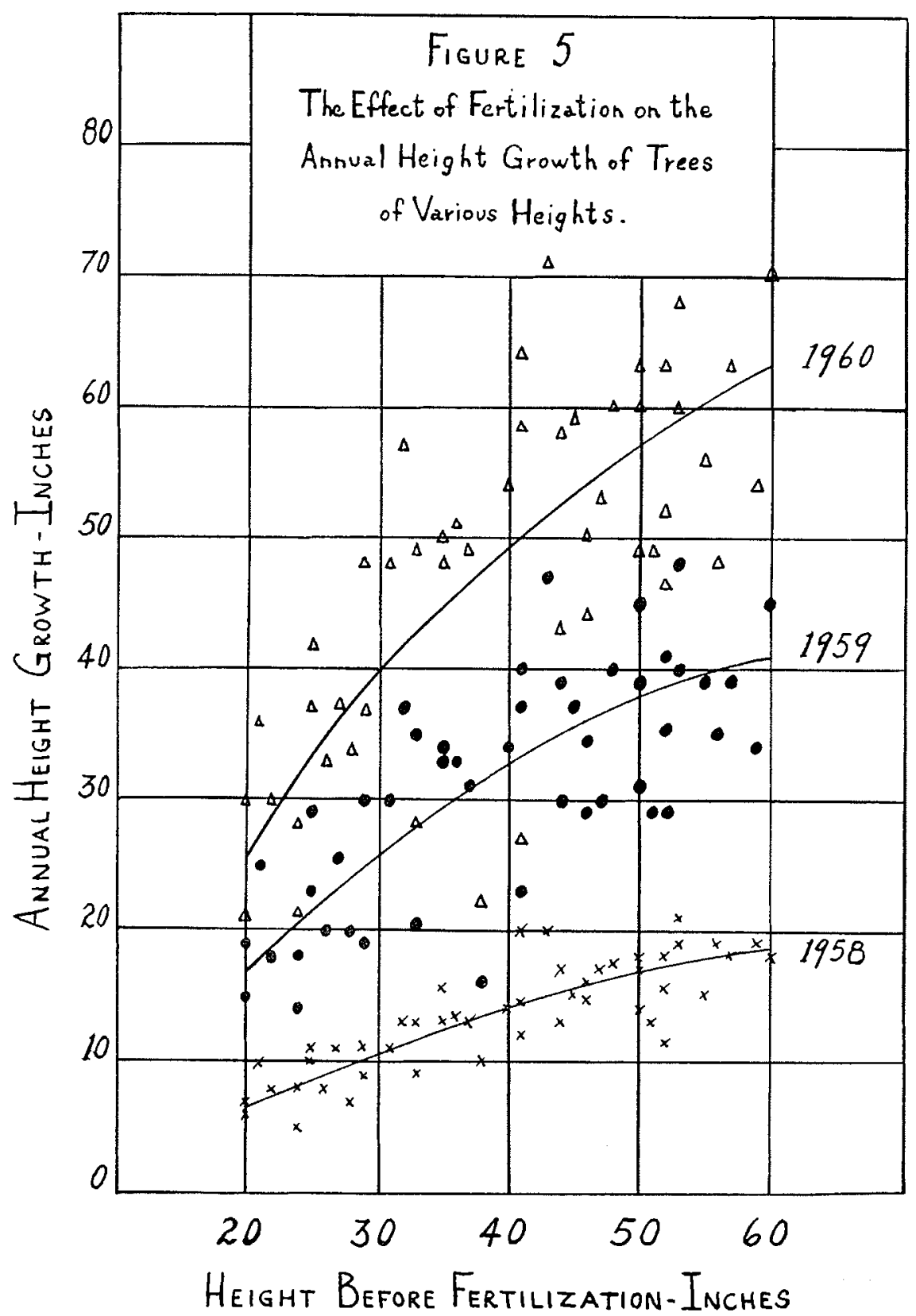


DECEMBER, 1963

TABLE 1

Fertilizer Treatments and Rates of Application

\begin{tabular}{rlrlc}
\hline & Fertilizer Treatment & Content & Rate-Ounces per Tree \\
\hline 1 & Ammonium sulfate & $20 \% \mathrm{~N}$ & 1.0 \\
2 & Ammonium sulfate & $20 \% \mathrm{~N}$ & 2.0 \\
3 & Ammonium sulfate & $20 \% \mathrm{~N}$ & 4.0 \\
4 & Ammonium sulfate & $20 \% \mathrm{~N}$ & 8.0 \\
5 & Ammonium sulfate & $20 \% \mathrm{~N}$ & 16.0 \\
6 & Uramite & $38 \% \mathrm{~N}$ & 2.1 \\
7 & Calcium cyanamide & $21 \% \mathrm{~N}+\mathrm{Ca}$ & 3.81 \\
8 & Calcium nitrate & $15 \% \mathrm{~N}+\mathrm{Ca} \quad$ & 5.33 \\
9 & Ammonium phosphate & $16 \% \mathrm{~N}+20 \% \mathrm{P}$ & 5.0 \\
10 & Milorganite & $5 \% \mathrm{~N}+3 \% \mathrm{P}$ & 16.0 \\
11 & Control & & \\
\hline
\end{tabular}

${ }^{1}$ The total nitrogen applied varied only in the ammonium sulfate treatments. All other treatments received the same total nitrogen and this was equivalent to the 4-ounce treatment of ammonium sulfate, or approximately $400 \mathrm{lbs}$. per acre.

\section{FOLIAR OBSERVATIONS}

All the fertilizers induced a deeper green in the needles formed in 1958. No change of needle color was noted in the control trees. The fertilizers produced longer needles on most fertilized trees. The calcium cyanamide killed two trees, and caused partial defoliation of 10 more. However, half the trees receiving this treatment showed no ill effects. One tree died under the 8-ounce ammonium sulfate treatment which also produced slight defoliation of older needles (prior to 1958) in four trees. Defoliation was heavier and more numerous under the 16-ounce ammonium sulfate treatment. Although Uramite is not supposed to injure roots, four trees receiving this treatment had partial defoliation after the first growing seanson. No needle disorders were noticed in the 1,2, and 4-ounce ammonium sulphate, calcium nitrate, ammonium phosphate and Milorganite treatments. A record kept of the initiation of height growth showed there was no advancement of growth initiation by any treatment when compared with the control. 


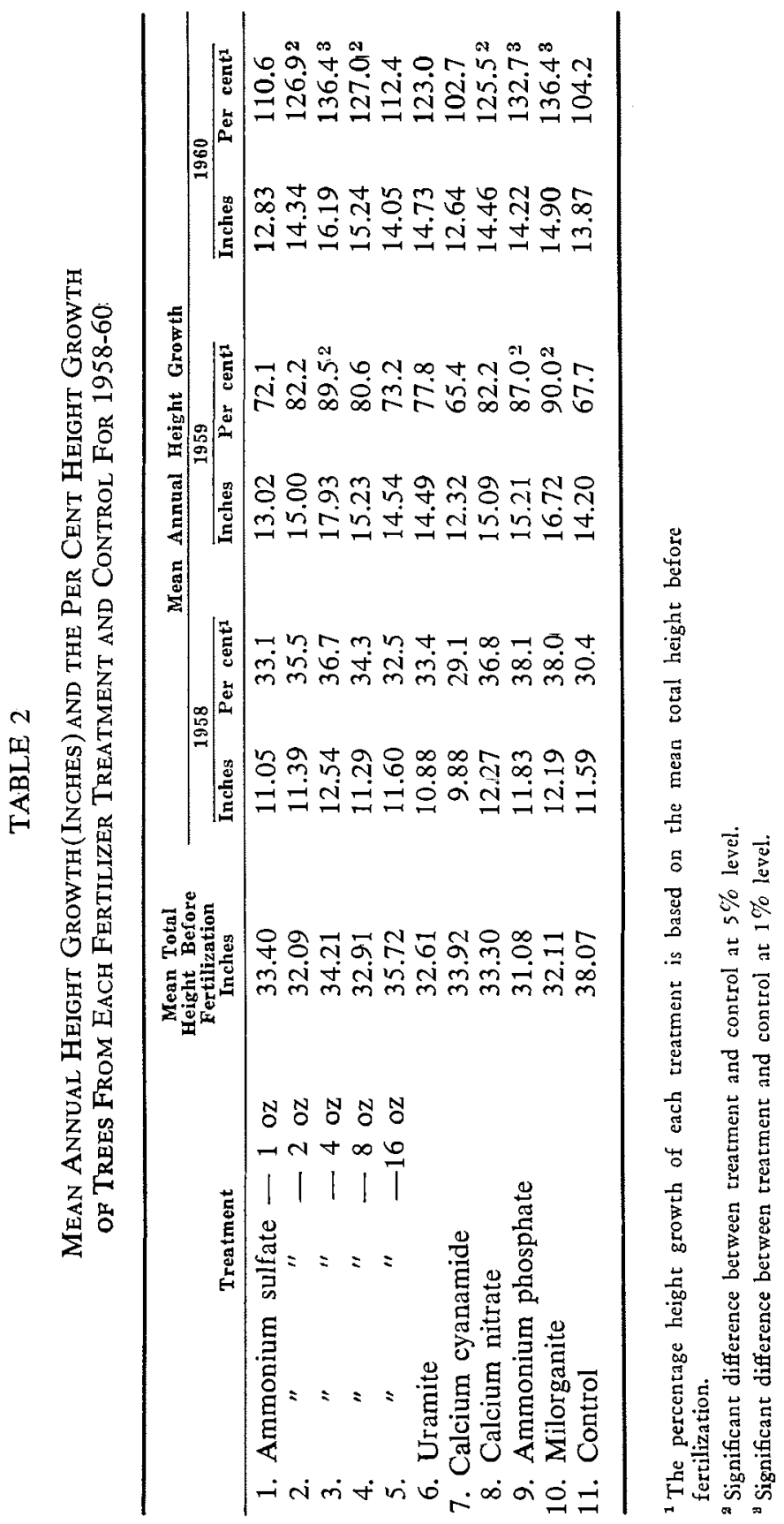




\section{CONCLUSION}

The three-year fertilizer trial indicates that productivity of low-quality site forest land may be raised appreciably by nitrogen fertilization. Fertilizers giving the best response were the Milorganite, ammonium phosphate and the 4-ounce ammonium sulfate. The growth response to the 4-ounce ammonium sulfate treatment indicated this rate of application to be optimum for this trial. However the variable responses suggest further fertilizer trials should be made on other sites at different seasons, for a longer period, and on other species at various ages. Future work should consider effects of fertilizers on wood quality, nutrient uptake and nutrient availability.

\section{ACKNOWLEDGEMENTS}

The author appreciated the excellent assistance in the field of Messrs. C. Pryce and M. Meagher of the British Columbia Forest Service, and is pleased to acknowledge the instructive review of the manuscript by Dr. S. P. Gessel of the College of Forestry, University of Washington.

\section{REFERENCES}

AUSTIN, R. C., and R. F. STRAND. 1960. The use of slowly soluble fertilizers in forest planting in the Pacific Northwest. Jour. For. 58(8): 619-627.

BAILEY, E. E, 1959. Some economic aspects of forest fertilization. Master of Forestry Thesis, University of Washington. $112 \mathrm{p}$.

GESSEL, S. P., and R. B. WALKER. 1956. Height growth response of Douglas fir to nitrogen fertilization. Soil Sci. Soc. Am. Proc. 20(1): 97-100.

HEILMAN, P. E. 1961. Effects of nitrogen fertilization on the growth and nitrogen nutrition of low-site Douglas-fir stands. Doctor of Philosophy Thesis, University of Washington. $214 \mathrm{p}$.

MILLER, R. E. 1961. A further analysis of thinning and fertilizing effects on growth of a thirty year old Douglas-fir stand. Master of Science in Forestry Thesis, University of Washington. $175 \mathrm{p}$.

SHAREEF, A. 1955. Thinning and fertilizing studies on a poor site at Pack Forest. Master of Forestry Thesis, University of Washington. $69 \mathrm{p}$.

WALTERS, J., J. SOOS, and P. G. HADDOCK. 1961. The influence of fertilizers on the growth of Douglas fir seedlings on the University of British Columbia Research Forest, Haney, B. C. University of British Columbia. Faculty of Forestry. Res. Note No. 31.6 p. 